\title{
Relações desiguais de gênero no discurso de adolescentes
}

\author{
Unequal gender relations in the speech of adolescents
}

Cássia Barbosa Reis ${ }^{1}$

N ayana Rosa dos Santos ${ }^{1}$
${ }^{1}$ U niversidadeEstadual do $M$ ato Grosso do Sul Rua Bertoldo M iranda de Barros 1113, Jardim Florida II. 79.822-110 Dourados MS. cassia@uems.br
Abstract Adolescence is a phase of life in which individuals experience rapid physical, emotional and intellectual change. In the midst of all these changes, distorted or incompleteinformation that adolescents receive on sexuality, including ST D/ AIDS, exposes them more readily to these diseases and early pregnancy. The scope of this work was to identify gender relations between adolescents. The method used was an analytical study with a qualitative approach based on social representations that examine values, beliefs, habits, attitudes and opinions in order to encompass the target group thoroughly. In analysis of the discourse, inequality was swiftly apparent with decidedly macho overtones. Despite the amount of information currently available on sexuality, many adolescents have precious little knowledge of the subject and a lack of adequate communication with their parents, their schools and the media. Key words Adolescents, SDT/AIDS, Gender
Resumo A adolescência éuma fase da vida ondeo indivíduo passa por rápidas mudanças físicas, emocionais eintelectuais. Em meio a todas essas alterações, as informações distorcidas ou incompletas que o jovem nessa etapa recebe sobre a sexualidade, incluindo as DST/Aids faz com que se exponha com maior facilidadea essas doenças eà gravidez precoce. 0 presente trabalho teve por objetivo identificar as relações de gênero entreos adolescentes, utilizando 0 estudo analítico com enfoque qualitativo, com base nas representações sociais que trabalha valores, crenças, representações, hábitos, atitudes e opiniões, de forma a abranger intensamente 0 grupo delimitado. $\mathrm{Na}$ análise do discurso ficou evidenciada a desigualdade, sendo reproduzida deforma machista. A pesar detoda informação que existe atualmente sobrea sexualidade, muitosadolescentes possuem déficit de conhecimento relacionado ao assunto efalta decomunicação adequada com os pais, a escola e a mídia.

Palavras-chave Adolescentes, DST/AIDS, Gênero 
Introdução

A adolescência éuma fase de transição na vida do ser humano, época de mudança que traz muitos questionamentos, e quando formam-se hábitos, atitudes e opiniões sobre diversos assuntos, dentre estes, os relacionados ao homem e à mulher, ou seja, às relações desiguais de gênero.

0 presente estudo abordou as relações de gênero ea forma como estas se projetam na mente do adolescente, contribuindo para que haja o desenvolvimento de ações que auxiliem a população estudada a repensar opiniões e a esclarecer dúvidas quanto a esse assunto.

N ota-se que há uma necessidade significativa de orientação sobre temas relacionados à sexualidade. Os pais e professores devem estar preparados para esclarecer dúvidas equestionamentos dos adolescentes, repassando conhecimento, e a mídia deve ousar da criatividade, abrindo espaço para que esse assunto possa ser mais divulgado, para que 0 adolescente saiba recepcionar informações sobreavida sexual, conscientizando-sedo certo eo errado, e assim, fiquem preparados para encarar a sexualidade de maneira responsável.

\section{M etodologia}

\section{Tipo de Estudo}

Estudo analítico com enfoque qualitativo que, segundo M inayo e Sanches ${ }^{1}$ éuma metodologia que "trabalha com valores, crenças, representações, hábitos, atitudes e opiniões" de forma a abranger intensamente o grupo delimitado.

\section{Local do Estudo}

A presente pesquisa foi realizada no Município de Dourados, Estado do M ato Grosso do Sul, na Escola Estadual Presidente Vargas.

\section{Sujeitos do Estudo}

A população selecionada para o estudo foi de adolescentes do ensino fundamental e médio.

Oscritérios de inclusão foram: estar entre 14 e 18 anos; matriculado(a) da 8a série do ensino fundamental ao 30 ano do ensino médio nos turnos matutino e vespertino; e não trabalhar.

Os critérios de exclusão foram: não aceitar ou não ser autorizado pelos pais/responsáveis a participar do estudo. A amostra foi, por conveniência, com 15 entrevistas, número que atingiu a saturação de respostas.

\section{Coleta de Dados}

A coleta de dados foi realizada através de roteiro deentrevista com adolescentes de uma escola estadual de Dourados. No qual estão contidos dados de identificação, no caso a idade, o sexo ea escolaridade, e as questões norteadoras do estudo sobre DST (1. Gostaria que me falasse: 0 que você sabe sobre doença sexualmente transmissível? Lembrar: causas; sintomas; consequências; transmissão; 2. Como você aprendeu essas coisas? Quem te falou?). No decorrer das entrevistas, apareceram frequentemente questões de gê nero nos discursos dos adolescentes, as partes das respostas que compõe este artigo.

Para a entrevista, a pesquisadora apresentou o objetivo do trabalho e o Termo de Consentimento Livre e Esclarecido, que foi assinado pelo pesquisado e pais/responsáveis, após leitura e esclarecimentos.

0 entrevistado teve o tempo necessário para relatar seu conhecimento sobre as relações desiguais de gênero. 0 entrevistador fez al gumas intervenções, quando necessário, para que o sujeito não divagasse.

As entrevistas foram realizadas na própria escola, em horário de intervalo dos estudantes. Estas entrevistas foram previamente agendadas com os sujeitos egravadas em fita $\mathrm{K} 7$ sendo transcritas imediatamente após o seu término.

\section{Período da Coleta de Dados}

Os dados foram colhidos no período de Se tembro/2006 a N ovembro/2006.

\section{Análise de Dados}

Os dados resultantes das entrevistas foram analisados considerando-se o Discurso do Sujeito Coletivo, proposto por Lefèvre e Lefèvre?

O Discurso do Sujeito Coletivo éuma técnica de tabulação e organização de dados qualitativos, apresentados através de um discurso desíntese, redigido na primeira pessoa do singular e elaborado com os mais significativos extratos de depoimentos de sentido semelhante. Fundamenta-sena Teoria das Representações sociais, econsiste em analisar as ideias centrais, as ancoragens eas expressões chaves, semel hantes, presentes nos discursos individuais.

\section{Princípios éticos}

O presente estudo seguiu as Diretrizes e N ormas de Pesquisa Envolvendo Seres Humanos ${ }^{3}$ e 
teve o protocolo de pesquisa aceito pelo Comitê de Ética de Pesquisa em Seres Humanos da Universidade Federal de M ato Grosso do Sul.

\section{Resultados ediscussão}

\section{Gênero}

\section{DSC}

Eu acho isso muito vulgar, principalmente da partedas mulheres, porqueelas, hojeelasnão sevalorizam, pros homens atéque isso é normal né, os homensacham, quesó prásmeninas émuito cedo, hoje tem crianças, de, crianças, né, não vou colocar adolescentes, mas crianças detreze, quatorzeanos quejá estão grávidas, né, às vezes vem lá, pela primeira menstruação já ficou grávida. As pessoas está indo muito cedo, tem guria de 14 eaté menos de 11 anos, ai já transei, eu fico pasma com um negócio desse, horrorizada, está muito precoce demais entre as meninas e os meninos. As meninas não tem consciência, as meninas mal sabem ainda como lidar com o seu próprio corpo, eéelasjá estão querendo conhe cer outros corpo, sem conhecer o seu próprio né. Eu vejo assim, os meninos olham para as meninas com roupas curtas. Acho que as meninas tem que usar roupas mais compridas, decentes. $E$ acho assim que os meninos tem ter mais respeito pelas meninas.

Esse discurso fala sobre a existência de diferenças nas relações de gênero, demonstran do que 0 adolescentecarrega a visão da sociedade antiga de que o homem a partir da faixa etária reprodutiva pode exercer livremente sua sexualidade, adqui rindo uma concepção de que essa prática é absolutamente normal para os homens, ocorrendo desvantagem entre as mulheres.

Atualmente, mesmo vivendo em outra realidade, com a legislação protegendo a mulher, quando se trata de sexualidade, o contexto histórico tem um poder maior, favorecendo o homem.

Segundo Scott ${ }^{4}$, a definição de gênero compõe-se de duas proposições: como um elemento constitutivo de relações sociais baseadas em diferenças percebidas entre os sexos e como forma primária de dar significado às relações de poder, colocando esse assunto nas relações sociais, ou seja, nas relações entre as pessoas. E é no ambiente social que o sujeito se faz homem e mulher, em um processo continuado e dinâmico, e de vida inteira no contexto social.

Existe um outro aspecto nas relações de gê nero que é a identidade subjetiva, aquela que 0 sujeito constrói na sociedade. Para Xavier Filha ${ }^{5}$, o sujeito possui várias identidades, desenvolvendo-as de maneira contraditória como, por exem- plo, de ser brasileiro, negro, etc. Ainda assegura que o papel de gênero, "éo conceito que se remete ao comportamento social, de modo que o sujeito revela aos outros que é homem ou mulher, ao passo que age no social".

A autora da citação acima revela quea identidade éa consciência que cada um tem de si mesmo, enquanto homem ou mulher, e portanto, a identidade sexual se refere aos papéis que cada indivíduo assume.

As pessoas possuem uma opinião predeterminada em relação ao estereótipo de gênero, estabelecendo uma separação dos indivíduos em categorias, projetando em sua mente as condutas que o homem ea mulher devem assumir perante a sociedade, condutas tais, que são específicas para cada um deles.

Para Viezzer ${ }^{6}$, quando se trabal ha conceitos de relações sociais de gênero significa aceitar que as relações entre homens e mulheres não são derivadas da biologia, poisnadajustifica quea partir da diferença biológica se construam modelos de relações sociais que impliquem a subordinação de um sexo a outro.

Existe ainda, em nossa sociedade, meios rígidos de controle da sexualidade feminina, onde os homens exercem a sua sexualidade com prazer eas mulheres reprimem o prazer carnal, dando lado para um prazer espiritual, como ser mãe. Desde pequenas, as mulheres não aprendem a se conhecer, ou seja, não conhecem o seu próprio corpo, não se tocam, não sentem prazer e preparam-se para serem mães, diferente da educação masculina. Esta última éincentivada a expressar menos emoção e afetividade, demostrando uma sexualidade genitalizada, o queinibe a realização plena na vida sexual, pois o processo histórico e cultural o conduz a concentrar sua sexualidade nos órgãos genitais ${ }^{5}$.

Outra diferença apresentada pela autora supra citada ${ }^{5}$ é que a masturbação, desde sociedades antigas, nunca foi cogitada na sexualidade feminina, onde a mulher não podia sentir prazer sexual, sendo al go somente atribuído aos homens. N este sentido, temostambém a mulher como alvo demuitas experiênciascientíficas cruéis, paratentar comprovar sua inferioridade biológica.

0 discurso enfatiza a menina como sendo indutora do ato sexual precoce, seja na maneira dese comportar na presença dos homens, na maneira de se vestir, além de não se cuidar no ato sexual, não seprevenindo contra uma gravidez precoceou doenças venéreas, sendo muitas vezes a culpada por esses acontecimentos, sem consciência da gravidade desses problemas, e que deve mudar algumas atitudes e comportamentos. Esse discurso 
somente aponta que o homem deve ter mais respeito pelamulher enão lembra que o homem também participa, possui responsabilidade por uma gravidez precoce e indesejada e na ocorrência de doenças sexualmente transmissíveis. As relações sexuais, com as mudanças conceituais e temporais, está se iniciando cada vez mais cedo e precisa de mais cuidado e observação por parte dos pais, professores e orientadores, para conduzir essas relações de uma maneira mais consciente, saudável, de modo que o adolescente possa adquirir responsabilidadeno ato sexual, eisto servetanto para as mulheres quanto para os homens.

A fecundidade precocevem preocupando especialistas do campo da saúde pela sua possível influência na vida reprodutiva futura. "Uma mulher que começa a sua vida reprodutiva mais cedo, maior ésua chance de terminá-la com uma fecundidade mais elevada"7 0 autor ainda ressalta que a gravidez na adolescência possui maiores chances de ocorrer mortalidade infantil e materna, problemas de saúde para a mulher como: hipertensão, maior incidência de eclâmpsia, infecções urinárias e anemias.

Existem fatores que influenciam a gravidez na adolescência, como o econômico, já que renda qualifica o comportamento da fecundidade. Em nosso país as jovens mais pobres se destacam pelas taxas de fecundidade mais elevada. Castro, et. al. ${ }^{7}$ concluíram que entre as mulheres de 15 a 19 anos que estavam inseridas em grupo familiar com até um salário mínimo, em 1991, a taxa defecundidadefoi calculada em $128 \%$, eentre as que estavam em um grupo familiar com dez salários mínimos ou mais, em $13 \%$.

A escolaridade da mãe também está associado a gravidez precoce:

0 menor número de filhos está estreitamente associado ao maior nível de escolarização da mãe. Além de indiretamente retardar a idade ao contrair o matrimônio e proporcionar à mulher mais acesso ao mercado de trabalho, a instrução assegura maior racionalidadereprodutiva, motivada pelas aspirações de criar e educar melhor os filhos e ampliar suas possibilidades de obter informações sobre métodos anticoncepcionais eficazes e de utilizá-los de forma adequada? ${ }^{7}$.

Esses fatores colaboram para uma gravidez precoce na adolescência, porém se os indivíduos dessa faixa etária forem instruídos devidamente no período escolar, se houver maior preocupação dos professores/as e pais nessa responsabilidade, menores serão as chances da adolescente engravidar. Cabe aos pais e professores o papel da orientação que é de suma importância para os adolescentes aprenderem a se relacionar de maneira segura, diminuindo as chances de uma gravidez indesejada precoce.

A escola acaba produzindo diferenças entre os gêneros, com uma pedagogia desigual e sexista. Como a família, a escola acaba delimitando como o menino ea menina devem se comportar e agir, determinando um estereótipo (que é uma forma rígida que reproduz comportamento de como devem agir as pessoas), onde o menino deve ser mais ativo e agressivo, e ligado à razão (sobressaindo na disciplina de matemática), já a menina deve ser mais quieta, meiga ecaprichosa, ligada à emoção, tendo mais dificuldade nas disciplinas que exigem mais raciocínio ${ }^{5}$.

A autora menciona ainda que o papel da escola é continuar com a educação informal que a criança recebe em seu lar, porém é na escola que se inicia a discriminação à mulher e seu trabalho de modelar as identidades feminina e masculina écontínuo e permanente.

A sexualidade está presente na escola na maneira como as pessoas, seja professores, orientadores ou alunos(as), vivenciam sua sexualidade. Segundo Xavier Filha5:

Assim como os pais, os professores educam para a vida sexual, pela sua forma particular deser, pelo fato de existirem como seres sexuados, que desempenham papeis correspondentes aos estereótipo masculino e feminino. A maneira como vivem e assumem a própria sexualidadee aceitam a sexualidade dos outros, em particular a dos/as alunos/as transparecenas suas atitudes eseus comportamentosem sala de aula.

\section{DSC}

As questões dos homossexuais, eu acho que se eles querem ser assim, se nasceu prá ser isso, tem que ser, eu não tenho preconceito, é o jeito deles, a gente tem o nosso, eu não tenho nenhum tipo de preconceito. As relações homossexuais, super visível em festas, em, nossa, em todo lugar, ruasem tudo quanto élugar tem, escolas, mesmo, maseu não sou contra, nem um pouco, mas tipo mudou, hoje é bem mais visível mesmo, antes era mais, uma coisa mais escondida etal, hojeninguém tá mais, nem aí, eu não tenho problema com ninguém, nem lésbica, nem hetero. Só que assi $m$, tem, eu acho queéculpa dos pais, porque eles ensinam que ser gay é errado e ser lésbica éfeio, que todo mundo vai texingar, que você não vai ter emprego que isso é ridículo, quem faz isso, e os alunos aprendem isso e mexe com os outros alunos daqui, quetem afeição feminina, não sei. Aí gera brigas, dá problemas, já deu atéprocesso aqui na escola, eassim. Eu tenho um amigo que ele éassim, eleénormal comigo, só tem essejeito delede gostar de homens, entendeu, eassim. 
Quanto às relações homossexuais, o discurso mostra que 0 adolescente não expressa preconceitos, dizendo que eles devem viver sua se xualidade de maneira com que se sintam bem, porém demonstra que esse tipo de relação mudou com o passar do tempo, enfatizando que gays e lésbicas se relacionavam de maneira mais reservada, mantendo relações às escondidas, mais discreta e que atual mente essa relação está visivelmente aberta e assumida para a sociedade.

A sexualidade sempre foi regida por normas morais, de forma que as maneiras de vivê-las foram construídas historicamente. A homossexualidadefoi vivida deforma diferenteem diversos períodos da história, mudando de acordo com a cultura de cada sociedade. A vivência da sexualidade tem seu lado positivo ou negativo, culposa ou não, com prazer ou desprazer, diferenciada para homens emulheres, de acordo com 0 seu entorno ${ }^{5}$.

A autora supracitada ainda faz uma relação entre as identidades de gênero e as sexuais, afirmando quea identidade sexual constitui-se pelas formas de viver a sensualidade, com parceiros/ as do mesmo sexo, do sexo oposto, de ambos os sexos ou sem parceiros/as. Por outro lado, as pessoas acabam se identificando socialmente e historicamente como masculinos e femininos, para construir as identidades de gênero.

0 discurso do sujeito coletivo demonstra ainda no trecho falando sobre homossexuais, que a educação rígida dos pais, que vem desdea sociedade antiga, critica e abomina as relações homossexuais, ensinando aos seus filhos a excluir esse grupo de pessoas, e que se optarem por seguir esse caminho serão também excluídos da sociedade, do grupo escolar e não conseguirão emprego e se profissionalizar.

Atualmente muitos pais já aceitam a opção sexual de seus filhos homossexuais, a mídia muitas vezes colabora para que muitas famílias que passam pela mesma situação aceitem essa opção, mas existem ainda muitas famílias que mantém a opinião rígida da sociedade histórica. Essa situação depende muitas vezes das relações entre pais e filhos, da existência do diálogo e compreensão no lar, do respeito de opiniões e pensamentos, para se concluir o lado positivo e negativo das relações homossexuais. Cada um sabe o queécerto emelhor a fazer, para se ter satisfação plena em sua vida.

As leis que regem a sociedade até pouco tempo não dava espaço a esse grupo de pessoas. A única certeza que se tem é que os homossexuais possuem uma força muito grande na sociedade, tanto que hoje eles não precisam se adequar às antigas leis e a viver com medo e insegurança, pois algumas leis se adequaram ao seu modo de vida, ou seja, a sociedade muda de acordo com a necessi dade e a satisfação da população, influenciando as leis que regem nosso mundo, o que permaneceéa consciência e o modo de pensar de cada ser humano.

Os primeiros casamentos entre pessoas do mesmo sexo foram realizados no Canadá, segundo uma publicação em um site de notícias, o BBC - Brasili ${ }^{8}$ dois casais homossexuais se casaram numa igreja em Toronto, no Canadá, ao encontrarem uma brecha na lei canadense, tornando-se, portanto, os primeiros casais homossexuais legalmente casados no país, mostrando que al guns lugares do mundo são garantidos a eles os mesmos direitos que aos casais heterossexuais, porém, outros ainda não reconhecem relações homossexuais como casamento, mas a liberdade para esse grupo está se expandindo constantemente.

Outra questão, relacionada aos homossexuais, muito polêmica na sociedade atual é a adoção de filhos por estes, que ainda não é devidamente legalizada. Esse assunto produz muitos questionamentos, pois existe uma controvérsia entrea não-adoção defilhos entre casais homossexuais que são legalmente casados e a liberação para adoção de filhos entre homossexuais solteiros. Segundo Gobbo":

0 preconceito entretanto faz com que a socie dade pereça, e muitas crianças sejam privadas de ter um lar, afeto, carinho, atenção. Precisamos romper a barreira da discriminação e permitir que o desejo da adoção, seja por casais homossexuais ou não, torne-se um instrumento efetivo na resolução dos problemas com as crianças que não tem lar nem identidade.

$E$, quanto à reação dos pais e das mães ante uma possível homossexualidade dos filhos e das filhas, vai desde uma plena aceitação até uma completa reprovação. A intensidade da reação, a duração de cada fase, e, sobretudo, o desenvolvimento da relação entre pais e filhos, irão depender, em grande medida, da informação prévia sobre a homossexualidade que possuem os pais. É conveniente conhecer os acontecimentos entre as famílias que enfrentam essa situação, quando a mesma se fez real e concreta. As primeiras reações geralmente são espontâneas, impensadas, e, possivelmente, agressivas. A situação nem sempre é evitável, dado que os pais também têm 0 direito de expor seus sentimentos de insatisfação e, não necessariamente, compreender ou aceitála prontamente. É importante que os pais e fiIhos concedam a si mesmos um tempo de adaptação à nova situação $0^{10}$. 
Enfim, o homossexualismo foi inteiramente condenado na sociedade europeia cristã como "contranatureza", mas recebeu no correr do tempo representações diferentes seja na pintura quanto na escultura, passando de querubim, anjocriança-juvenil, semi-assexuado, semi-afeminado à imagem viril, esportista jovem e bronzeado ou motoqueiro de roupas de couro negro, brinco numa orelha, lábios carnudos, e cabelos sedosos. Ou seja, em cada época, os valores, símbolos, fantasias e relações com outras dimensões da vida social acabam determinando a imagem e o sentido de uma figura que apenas designando como homossexual poderia ser considerada a mesma sempre. Com o passar do tempo as formas de repressão e as respostas a ela se formalizam de maneira diferente ${ }^{11}$.

$\mathrm{Na}$ análise do discurso sobre gênero é possível identificar a distinção entre os sexos, onde o adolescente forma em sua mente, por influência da sociedade, parâmetros relacionados às atribuições que o homem e a mulher deve ter. Os homens e as mulheres são diferentes biologicamente, mas não são desiguais.

\section{Considerações finais}

Os resultados sobre gênero identificados e analisados durante a pesquisa são importantes para a identificação do nível de conhecimento que o adolescente possui sobre 0 assunto.

\section{Referências}

1. Minayo M CS, Sanches O. Quantitativo-qualitativo: oposição ou complementaridade? Cad Saude Publica 1993; 9(3):239-362.

2. Lefèvre $F$, Lefèvre AMC. 0 discurso do sujeito coletivo: um novo enfoque em pesquisa qualitativa (desdobramentos). Caxias do Sul: EDUCS; 2003.

3. Brasil. M inistério da Saúde (MS). Fundação Nacional de Saúde. Centro Nacional de Epidemiologia. Normas de pesquisa envolvendo seres humanos Resolução 196/96. Informe Epidemiológico do SUS 1996; 2(Supl.3):13-30.

4. Scott J. Gênero: U ma Categoria útil para análise histórica. Educação e Realidade 1995; 20(2):71-99.

5. Xavier Filha C. Educação Sexual na Escola: O Dito e o Não-Dito na Relação Cotidiana. Campo Grande (MS): UFM S; 2000.

6. Viezzer M. 0 problema não está na mulher. São PauIo: Cortez; 1989.
Apesar de toda informação que existe atualmente, muitos adolescentes ainda possuem déficit de conhecimento, além das informações que são recebidas de maneira distorcida.

Os pais devem se conscientizar de seu papel na educação sexual de seus filhos, tentando minimizar os tabus impostos pela sociedade que eles próprios carregam desde sua adolescência.

O M inistério da Educação, juntamente com o M inistério da Saúde, precisa investir mais nessa questão, inserindo nas escolas disciplinas que enfatizem a importância de se aprender não somente a anatomia e a fisiologia do aparelho reprodutor, mas também discutir a sexualidade e suas implicações, com enfoquepsicológico e preventivo, com o adolescente de hoje.

A fase jovem da vida do ser humano é com certeza uma das fases mais reflexivas, em que 0 adolescente passa a vivenciar as mudanças corpóreas, intelectuais e emocionais, eé nessa etapa que ele deve estar preparado para os desafios eas armadilhas que o mundo proporciona, sendo importante que adquira o máximo de informações possíveis sobre diversos assuntos, inclusive sobre a sexualidade.

As várias questões abordadas no presentetrabalho podem contribuir para que haja um aumento em pesquisas e ações voltadas para 0 adolescente e a sexualidade, incluindo informações sobre a formação das identidades masculina e feminina.
7. Castro MG, Abramovay M, Silva LB. Juventudes e sexualidade. Brasília: Unesco Brasil; 2004.

8. Primeiros casamentos gays realizados no Canadá. BBC - Brasil 2001; 15 jan. [acessado 2007 jul 10]. Disponível em: http://www.bbc.co.uk/portuguese/ noticias/2001/010115_gays.shtml

9. Gobbo E. Adoção por casais homossexuais. [acessado 2007 jul 10]. Disponível em: http://www.pailegal. net/chicus.asp?rvTextold $=-1258476700$

10. Igrejas da Comunidade M etropolitana Brasil (ICM - Brasil). Guia para pais de filhos homossexuais. [acessado 2007 jul 10]. Disponível em: http://www. icmbrasil.org/index.htm?guia.htm principal

11. Chauí M. Repressão Sexual: essa nossa (des)conhecida. 7ạ ed. São Paulo: Brasiliense; 1984. 